\title{
Pharmacokinetics and Safety of Intravenous and Subcutaneous Auto-injector Single-dose Belimumab in Healthy Chinese Volunteers: A phase 1, Randomized, Open-label Study
}

\author{
Xianmin Meng • Qianqian Wang $\cdot$ Shunquan $\mathrm{Wu} \cdot \mathrm{Di} \mathrm{Pu} \cdot$ \\ Amber Zhang $\cdot$ Sun Fang $\cdot$ Xuan Zhou $\cdot$ Hongzhou Lu (D)
}

Received: May 25, 2021 / Accepted: August 25, 2021 / Published online: September 23, 2021

(c) The Author(s) 2021

\begin{abstract}
Introduction: Belimumab is a recombinant

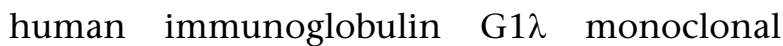
antibody indicated as an intravenous (IV) $10 \mathrm{mg} / \mathrm{kg}$ and subcutaneous (SC) 200-mg dose for the treatment of systemic lupus erythematosus (SLE). Belimumab $10 \mathrm{mg} / \mathrm{kg}$ IV has been approved for the treatment of patients with SLE in China. This phase 1 study investigated the pharmacokinetics (PK), safety, and
\end{abstract}

Supplementary Information The online version contains supplementary material available at https:// doi.org/10.1007/s40744-021-00366-0.

\section{Meng}

Department of Pharmacy, Shanghai Public Health Clinical Center, Fudan University, Shanghai, China

Q. Wang

Department of Internal Medicine, Shanghai Public Health Clinical Center, Fudan University, Shanghai, China

S. Wu $\cdot$ D. Pu $\cdot$ A. Zhang $\cdot$ S. Fang

R\&D, GlaxoSmithKline, Shanghai, China

\section{Zhou}

Clinical Pharmacology Modelling and Simulation, GlaxoSmithKline, Shanghai, China

H. Lu ( $\square)$

Department of Infectious Diseases and Immunology, Shanghai Public Health Clinical Center, Fudan University, 2901 Caolang Rd, Jinshan District, Shanghai, China

e-mail: luhongzhou@fudan.edu.cn tolerability of belimumab $200 \mathrm{mg}$ SC and the approved IV formulation in a healthy Chinese population.

Methods: This was a 13-week open-label, randomized, parallel-group study in healthy Chinese volunteers. Eligible volunteers were randomized (1:2) to receive a single dose of IV or SC (via auto-injector) belimumab $200 \mathrm{mg}$. PK and safety endpoints were evaluated using descriptive statistics.

Results: Thirty-six healthy Chinese volunteers were enrolled and all completed the study. Concentration-time profiles were as expected for both formulations. Overall, 130 adverse events (AEs) were reported, with 28 AEs reported in $11(91.7 \%)$ volunteers in the IV group and 102 AEs in $24(100 \%)$ volunteers in the SC group. Of the 130 AEs, 104 (80.0\%) were considered to be treatment-related (27 [20.8\% of total AEs] treatment-related AEs in the IV group; 77 [59.2\% of total AEs] in the SC group). Although the occurrence of AEs was higher in the SC group, most volunteers $(91.7 \%)$ experienced AEs of mild intensity. The most frequently reported AEs included injection site pain $(n=19$ [79.2\%]) and oropharyngeal pain $(n=5$ [20.8\%]) in the SC group, and positive bacterial test, upper respiratory tract infection, blood uric acid increase, white blood cell count increase, asthenia, and diarrhea $(n=2$ [16.7\%], each) in the IV group.

Conclusions: PK profiles of $200 \mathrm{mg}$ SC and IV belimumab administrations were similar to 
previous studies, and safety profiles were acceptable, supporting the use of the SC dose in Chinese patients with SLE.

Trial registration: NCT04136145.

\section{PLAIN LANGUAGE SUMMARY}

Systemic lupus erythematosus (SLE) is a longterm autoimmune disease that affects patients' quality of life. Belimumab is an antibody used in several countries in combination with standard therapy to treat patients with SLE. Belimumab can be given monthly either via a vein (intravenous, IV) or weekly under the skin (subcutaneous, SC). In China, only the IV belimumab has been approved for the treatment of patients with SLE. Therefore, we carried out a study in healthy Chinese volunteers to compare the concentration of a single dose of IV or SC belimumab in the body over time, and to investigate the safety of SC belimumab to assist its approval in China. In our study, the concentration and safety of both administration methods were similar; however, more volunteers from the SC treatment group had urinalysis-related side effects compared with the IV treatment group. All of these side effects were of mild intensity and did not require treatment. These results suggest that SC belimumab could be used for the treatment of Chinese patients with SLE.

Keywords: Belimumab; Intravenous; Monoclonal antibody; Pharmacokinetics; Safety; Subcutaneous; Systemic lupus erythematosus

\section{Key Summary Points}

Why carry out this study?

Systemic lupus erythematosus (SLE) is a chronic autoimmune disease having a 2-3 times higher prevalence and incidence rate in Asian populations than in the Caucasian population.
Belimumab, a recombinant immunoglobulin G1 $\lambda$ human monoclonal antibody that binds and neutralizes B-lymphocyte stimulator, is approved for the treatment of SLE in several countries via monthly intravenous (IV) $10 \mathrm{mg} / \mathrm{kg}$ doses or weekly subcutaneous (SC) 200-mg doses. However, the belimumab $200 \mathrm{mg}$ SC formulation is not approved for the treatment of SLE by the Chinese National Medical Products Administration.

The current open-label, randomized, single-dose, phase 1 study (GSK Study 209629; NCT04136145) was conducted to investigate the pharmacokinetics (PK) and safety of belimumab $200 \mathrm{mg}$ SC (via autoinjector) and the approved IV formulation $(200 \mathrm{mg})$ in 36 healthy Chinese volunteers.

\section{What was learned from the study?}

The concentration-time profiles of belimumab $200 \mathrm{mg}$ IV and SC demonstrated similar exposure after single dosing in healthy Chinese volunteers.

Concentration-time profiles of belimumab $200 \mathrm{mg}$ SC and IV administrations in healthy Chinese volunteers were similar to previous studies. Safety and tolerability profiles were acceptable; however, a greater proportion of volunteers from the SC treatment group experienced urinalysisrelated AEs compared with the IV treatment group. All urinalysis-related AEs were of mild intensity and resolved without treatment. These findings support the use of the SC dose in Chinese patients with SLE.

\section{INTRODUCTION}

Systemic lupus erythematosus (SLE) is a chronic disease characterized by elevated levels of autoantibodies and persistent autoimmune 
activation of B cells, which can lead to organ damage [1-7]. SLE is associated with a broad spectrum of clinical manifestations that may substantially impact health-related quality of life of patients with SLE $[8,9]$. The incidence of SLE per 100,000 person-years is 7.2-23.2 in the USA [10, 11], 1.0-3.6 in Denmark [12], 3.0-4.9 in the UK [13-15], 2.5-2.8 in South Korea [16], 3.1-6.7 in Chinese populations $[17,18]$, and $3.0-8.4$ in Taiwan $[19,20]$. In terms of race, the prevalence and incidence rates of SLE are approximately 2-3 times higher in the Asian population compared with the Caucasian population [21]. Additionally, patients of Asian descent with SLE have been reported to experience more severe disease, a higher incidence of renal involvement, and a higher proportion of autoantibody positivity than non-Asian individuals with SLE [22].

The current treatment of SLE focuses on targeting B cells and their stimulators owing to their key role in the pathogenesis of the disease $[23,24]$. Belimumab is a recombinant human immunoglobulin G1 monoclonal antibody that binds to B-lymphocyte stimulator (BLyS), neutralizing its activity [25]. The efficacy and safety of belimumab have been shown in patients with active SLE in several phase 2 and phase 3 clinical trials [5, 7, 26-28]. The data from these studies have also suggested that belimumab may have a corticosteroid-sparing effect $[5,7,26,27]$. Monthly doses of intravenous (IV) belimumab $10 \mathrm{mg} / \mathrm{kg}$ or weekly doses of subcutaneous (SC) belimumab $200 \mathrm{mg}$ are indicated for the treatment of SLE in addition to standard therapy in several countries $[25,29-31]$. Belimumab $10 \mathrm{mg} / \mathrm{kg} \quad \mathrm{IV}$ is approved for the treatment of patients with SLE in China [32, 33], however the efficacy and safety of SC belimumab have not yet been evaluated among Chinese patients. Therefore, the current study was conducted to investigate the pharmacokinetics (PK) and safety of belimumab $200 \mathrm{mg}$ SC and the approved IV formulation in healthy Chinese volunteers. This study was designed to demonstrate similar exposure after single SC and IV dosing to support the approval of the belimumab $200 \mathrm{mg} \mathrm{SC}$ formulation in China.

\section{METHODS}

\section{Study design}

This was an open-label, randomized, parallelgroup, single-dose, phase 1 study (GSK Study 209629; NCT04136145) in healthy Chinese volunteers. This study was conducted between October 28, 2019 and January 14, 2020 at the Shanghai Public Health Clinical Center, Shanghai. All eligible volunteers were randomized $(1: 2)$ to receive a single dose of either belimumab $200 \mathrm{mg}$ IV or belimumab $200 \mathrm{mg}$ SC. A parallel design was selected as the terminal halflife of belimumab is longer than 2 weeks (18 days) based on the previous population PK analysis [34]. The randomization was stratified based on body weight ( $<65 \mathrm{~kg}$ and $\geq 65 \mathrm{~kg}$ ). A total of $250 \mathrm{ml}$ IV dose was infused over $1 \mathrm{~h}$ and the SC dose was administered via an auto-injector device into the front of the thigh within 15 s. As shown in Fig. 1, the total study duration including screening was approximately 13 weeks, with the final assessments taken on day 71 post-dosing.

The study was approved by the ethics committee of Shanghai Public Health Clinical Center (2019-E035-03), and conducted in accordance with the International Council on Harmonization of Technical Requirements for Registration of Pharmaceuticals for Human Use, Good Clinical Practice ethical principles, and the Declaration of Helsinki. Written informed consent was obtained from each volunteer prior to the performance of any study-specific procedures. The informed consent form provided a detailed description of the safety risks, including possible serious adverse reactions or risks, common adverse reactions, and effects on pregnancy.

\section{Study participants}

Eligible participants were healthy Chinese volunteers between 18 and 45 years of age, with a body weight of at least $45 \mathrm{~kg}$ for females and $50 \mathrm{~kg}$ for males, with a body mass index between 19.0 and $26.0 \mathrm{~kg} / \mathrm{m}^{2}$, and non-smokers 


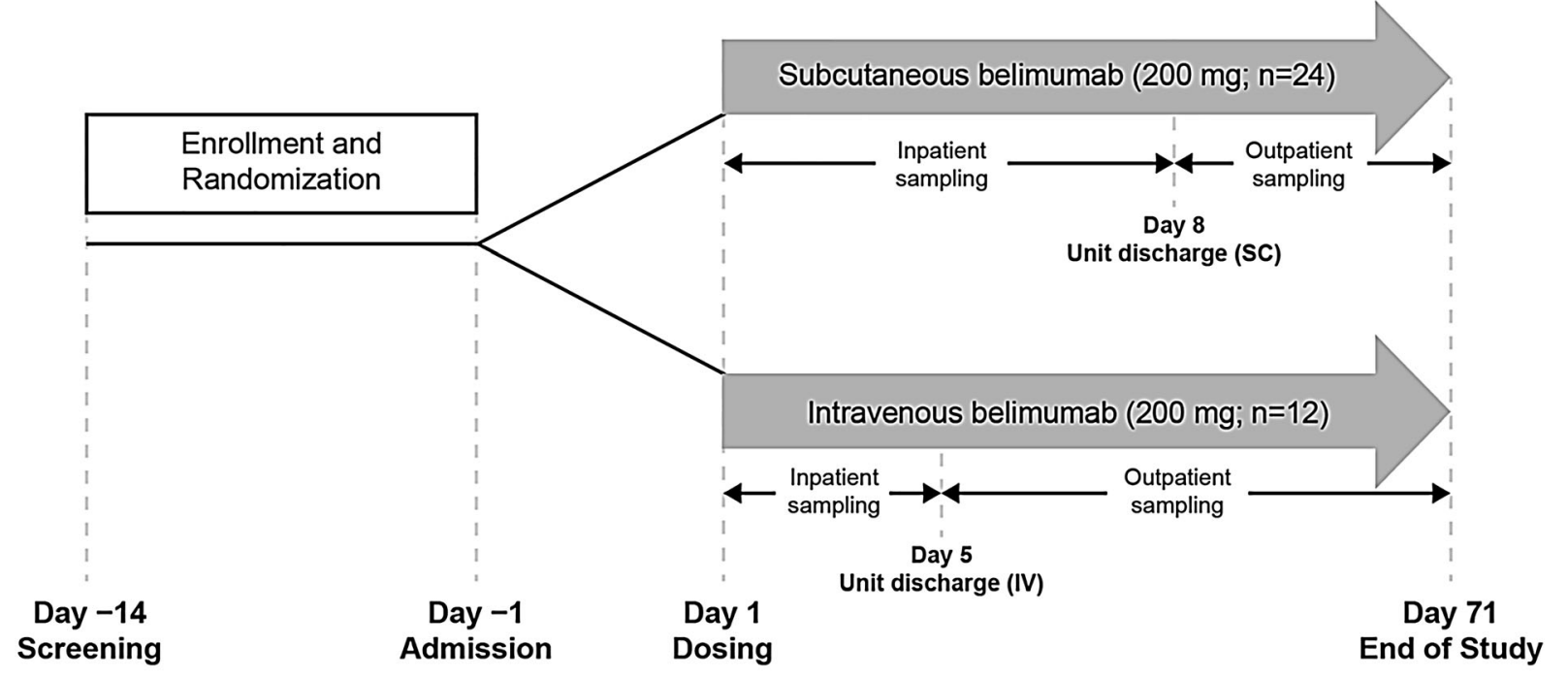

Fig. 1 Study design. $I V$ intravenous, $S C$ subcutaneous

or ex-smokers (if they had ceased smoking for at least 6 months prior to initiation of this study).

Main exclusion criteria included current or chronic history of liver disease or known hepatic or biliary abnormalities (except for Gilbert's syndrome or asymptomatic gallstones), history of malignant neoplasm within the last 5 years (except for adequately treated basal or squamous cell cancers of the skin or carcinoma in situ of the uterine cervix), and B-cell-targeted therapy at any time. Complete exclusion criteria are listed in the Supplementary Materials.

Female volunteers of child-bearing potential were eligible to participate in this study if they agreed to use a highly effective method of contraception consistently and correctly (a list of contraceptive methods is provided in Supplementary Table 1). Female volunteers were only included after a confirmed menstrual period and a negative highly sensitive serum pregnancy test performed and assayed at day -1 . Additional urine pregnancy testing was required at screening, day 29 , day 57 , and day 71 and whenever a menstrual cycle was missed or when pregnancy was suspected. Pregnancy within 16 weeks after day 71 were assessed with home kits and volunteers could report the results via their phone to the site.

\section{Study endpoints}

The primary endpoint of this study was to characterize the PK profile of belimumab $200 \mathrm{mg}$ after IV and SC administration via autoinjector in healthy Chinese volunteers. For this purpose, blood samples were collected at regular intervals from volunteers in both treatment groups. For the IV belimumab treatment group, blood samples were collected at: pre-dose, $-0.5,0,1,6,24,48,72,96,168,336,504,672$, 1008,1344 , and $1680 \mathrm{~h}$ relative to the time of dosing. The -0.5 -h time point was $30 \mathrm{~min}$ after the start of the IV infusion and 0-h time point was the end of the hour-long IV infusion. For the SC belimumab treatment group, blood samples were collected at: pre-dose, 6, 24, 48, 72, 96, 120, 144, 168, 240, 336, 504, 672, 1008, 1344 , and $1680 \mathrm{~h}$ relative to the time of dosing. Belimumab serum concentrations were measured using a MESO QuickPlex SQ 120 with a validated electrochemiluminescence analytical method by Meso Scale Discovery analysis, which had lower and upper limits of quantification of $100 \mathrm{ng} / \mathrm{ml}$ and $12,800 \mathrm{ng} / \mathrm{ml}$, respectively. Quality control (QC) samples (containing belimumab at three different concentrations and stored with study samples) were analyzed with each batch of samples against separately prepared calibration standards. To be 
considered acceptable, no more than one-third of the QC results were to deviate from the nominal concentration by more than $\pm 20 \%$, and at least half of the results from each QC concentration were to be within $\pm 20 \%$ of nominal concentration. All analytical runs met predefined run acceptance criteria. Mean (standard deviation [SD]) concentration-time by treatment group were plotted on both linear and semi-log scales.

The key secondary endpoint was safety and tolerability, assessed by monitoring of adverse events (AEs), injection site reactions, clinical laboratory tests, electrocardiogram (ECG), and vital signs. AEs were collected from the start of treatment until the follow-up visit on day 71 .

\section{Statistical analysis}

No formal sample size sensitivity analysis was performed. The sample size was determined based on a minimum required sample size of 20 , as per the Chinese Regulatory Guidance for a phase 1 clinical trial [35]. Therefore, the initial aim was to evaluate 20 volunteers in the SC belimumab treatment group but to adjust the sample size for the IV belimumab treatment group to ten due to the lower variability observed for IV belimumab in previous clinical trials. However, the sample size was increased to 36 , assuming a dropout rate of $20 \%$, to obtain at least 20 evaluable volunteers in the SC group and ten evaluable volunteers in the IV group. The safety population was defined as all randomized volunteers who received one dose of study treatment and the PK population was defined as all volunteers from the safety population for whom $\geq 1$ evaluable PK sample was obtained and analyzed. No power calculations were performed; therefore PK and safety endpoints were evaluated using descriptive statistics. AEs were coded using the Medical Dictionary for Regulatory Activities (MedDRA) and summarized by system organ class (SOC) and preferred term. The number and percentage of volunteers with any AEs occurring on or after treatment were summarized by treatment group. The AEs related to injection site reactions were summarized for SC group only.

\section{RESULTS}

\section{Participant disposition and baseline demographics}

A total of 171 volunteers were screened, of which $36(21.1 \%)$ were enrolled in the study. Reasons for screening failure included 131 (76.6\%) volunteers not meeting the inclusion/ exclusion criteria, one $(0.6 \%)$ volunteer was failed based on investigator discretion, and three $(1.8 \%)$ withdrew consent. Of the 36 volunteers enrolled in this study, 12 were randomized to the IV group and 24 to the SC group. All 36 volunteers completed the study. The baseline demographics were similar across both IV and SC belimumab groups (Table 1). The mean age of the volunteers was 28.7 years and majority $(81 \%)$ were male.

\section{Pharmacokinetic results}

Mean (SD) concentration/time profiles of belimumab were obtained for belimumab $200 \mathrm{mg}$

Table 1 Baseline demographics (safety population)

\begin{tabular}{|c|c|c|}
\hline & $\begin{array}{l}\text { Belimumab } \\
200 \mathrm{mg} \text { IV } \\
n=12\end{array}$ & $\begin{array}{l}\text { Belimumab } \\
200 \mathrm{mg} \mathrm{SC} \\
n=24\end{array}$ \\
\hline $\begin{array}{l}\text { Age } e^{a} \text {, years, mean } \\
\quad(\mathrm{SD})\end{array}$ & $27.9(3.99)$ & $29.1(6.44)$ \\
\hline \multicolumn{3}{|l|}{ Sex, $n(\%)$} \\
\hline Female & $3(25.0)$ & $4(16.7)$ \\
\hline Male & $9(75.0)$ & $20(83.3)$ \\
\hline $\begin{array}{r}\text { BMI, } \mathrm{kg} / \mathrm{m}^{2}, \\
\text { mean }(\mathrm{SD})\end{array}$ & $22.4(1.89)$ & $22.1(1.69)$ \\
\hline $\begin{array}{l}\text { Height, } \mathrm{cm} \text {, mean } \\
\text { (SD) }\end{array}$ & $166.7(7.68)$ & $167.8(6.52)$ \\
\hline $\begin{array}{l}\text { Weight, kg, mean } \\
\text { (SD) }\end{array}$ & $62.7(9.06)$ & $62.6(7.09)$ \\
\hline
\end{tabular}

$B M I$ body mass index, $I V$ intravenous, $S C$ subcutaneous, $S D$ standard deviation

a Age is imputed when full date of birth is not provided 
IV and belimumab $200 \mathrm{mg}$ SC (Fig. 2). In the IV group, the mean (SD) serum belimumab concentration increased from $0(0.0) \mathrm{ng} / \mathrm{ml}$ predose to $64,474.6(9167.2) \mathrm{ng} / \mathrm{ml}$ at $1 \mathrm{~h}$ (day 1) post-dose. The concentration then progressively decreased to $10,115.7(2290.0) \mathrm{ng} / \mathrm{ml}$ at $672 \mathrm{~h}$ (day 29) and to $1916.6(936.5) \mathrm{ng} / \mathrm{ml}$ at $1680 \mathrm{~h}$ (day 71) post-dose (Table 2). In the SC group, the mean (SD) serum belimumab concentration increased from $0(0.0) \mathrm{ng} / \mathrm{ml}$ pre-dose to 963.8 (875.5) $\mathrm{ng} / \mathrm{ml}$ at $6 \mathrm{~h}$ (day 1) post-dose, and reached the peak of $17,262.9(3702.0) \mathrm{ng} / \mathrm{ml}$ at $240 \mathrm{~h}$ (day 11). The concentration then progressively decreased to 7551.1 (2836.1) $\mathrm{ng} / \mathrm{ml}$ at $672 \mathrm{~h}$ (day 29) and to 1365.7 (931.5) $\mathrm{ng} / \mathrm{ml}$ at $1680 \mathrm{~h}$ (day 71) post-dose (Table 2).

\section{Safety results}

A total of 130 AEs were reported in this study, with 28 (21.5\%) AEs reported in 11 (91.7\%) volunteers in the IV group and $102(78.5 \%)$ AEs reported in 24 (100\%) volunteers in the SC group. The AEs were of mild $(95.4 \%, n=124$ / $130)$ or moderate $(4.6 \%, n=6 / 130)$ severity.

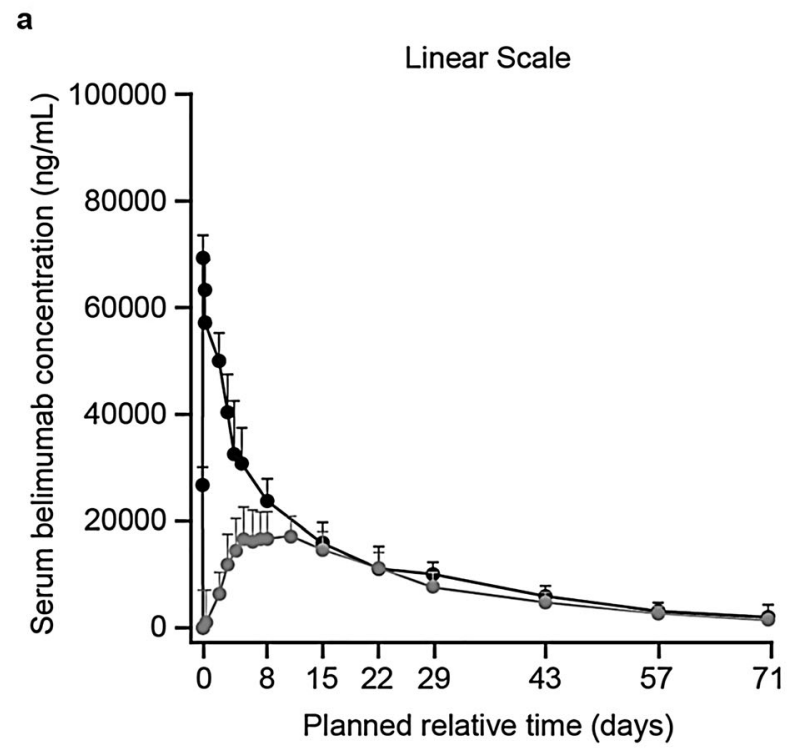

$\rightarrow$ Belimumab 200 mg IV

Fig. 2 Mean (+ SD) belimumab concentration-time plots for the belimumab $200 \mathrm{mg}$ IV and SC treatment groups (a linear and $\mathbf{b}$ semi-log; PK population; IV,
The most frequently reported AEs in the IV group included diarrhea, asthenia, upper respiratory tract infection, positive bacterial test, blood uric acid increase, and white blood cell (WBC) count increase (16.7\% each; Table 3). The most frequently reported AEs in the SC group included injection site pain (79.2\%), oropharyngeal pain $(20.8 \%)$, mouth ulceration $(16.7 \%)$, positive bacterial test $(16.7 \%)$, neutrophil count decrease (16.7\%), and occult blood positive (16.7\%; Table 3 ). Most of the AEs (85.4\%) resolved during the study.

Overall, $80 \%$ of total AEs were considered by the investigator to be treatment-related; treatment-related events were reported in $83.3 \%$ of volunteers in the IV group and $91.7 \%$ of volunteers in the SC group (Table 3). The most frequently reported treatment-related AEs in the IV group included diarrhea, positive bacterial test, blood uric acid increase, WBC count increase, upper respiratory tract infection, and asthenia (16.7\% each; Table 3$)$. The most frequently reported treatment-related AEs in the SC group included oropharyngeal pain (20.8\%), mouth ulceration, positive bacterial test,

b

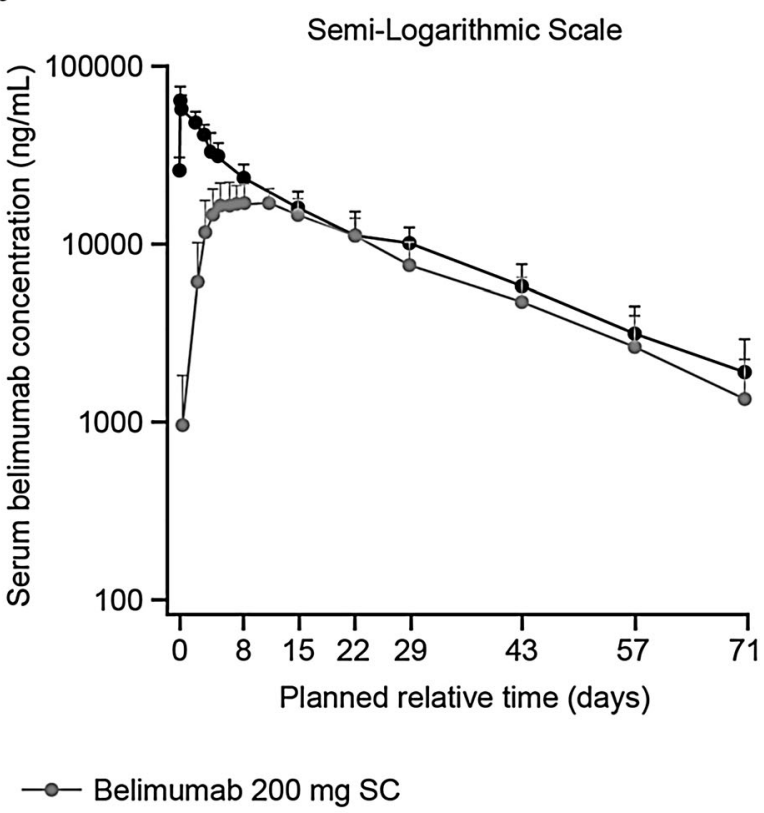

$n=12$; SC, $n=24)$. $I V$ intravenous, $P K$ pharmacokinetic, $S C$ subcutaneous, $S D$ standard deviation 
Table 2 Serum belimumab concentration-time data ( $\mathrm{ng} / \mathrm{ml}$; PK population)

\begin{tabular}{|c|c|c|c|c|c|}
\hline \multirow[t]{2}{*}{$\begin{array}{l}\text { Planned relative } \\
\text { time }\end{array}$} & \multicolumn{2}{|c|}{$\begin{array}{l}\text { Belimumab } 200 \mathrm{mg} \mathrm{IV} \\
n=12\end{array}$} & \multirow[t]{2}{*}{$\begin{array}{l}\text { Planned relative } \\
\text { time }\end{array}$} & \multicolumn{2}{|c|}{$\begin{array}{l}\text { Belimumab } 200 \mathrm{mg} \mathrm{SC} \\
n=24\end{array}$} \\
\hline & Mean (SD) & Median (min., max.) & & Mean (SD) & Median (min., max.) \\
\hline Pre-dose & $0.0(0.0)$ & $0.0(0,0)$ & Pre-dose & $0.0(0.0)$ & $0.0(0,0)$ \\
\hline $\begin{array}{l}30 \text { min start IV } \\
(\text { day } 1)\end{array}$ & $\begin{array}{l}26,567.4 \\
(3602.7)\end{array}$ & $\begin{array}{l}27,245.6(20,616 \\
30,897)\end{array}$ & 6 h (day 1) & $963.8(875.5)$ & $742.5(114,4093)$ \\
\hline $0 \mathrm{~h}$ (day 1$)$ & $\begin{array}{l}63,403.2 \\
\quad(6104.6)\end{array}$ & $\begin{array}{l}64,504.5(50,656 \\
71,552)\end{array}$ & 24 h (day 2) & $\begin{array}{l}6255.4 \\
(4255.2)\end{array}$ & $\begin{array}{l}4905.6(1010 \\
16,708)\end{array}$ \\
\hline $1 \mathrm{~h}($ day 1$)$ & $\begin{array}{l}64,474.6 \\
(9167.2)\end{array}$ & $\begin{array}{l}66,965.3(49,492 \\
78,162)\end{array}$ & 48 h (day 3) & $\begin{array}{l}11,838.9 \\
(5838.5)\end{array}$ & $\begin{array}{l}11,345.7(2657 \\
25,531)\end{array}$ \\
\hline $6 \mathrm{~h}$ (day 1$)$ & $\begin{array}{l}57,450.1 \\
\quad(7804.5)\end{array}$ & $\begin{array}{l}59,956.6(41,827 \\
66,979)\end{array}$ & 72 h (day 4) & $\begin{array}{l}14,501.9 \\
(6105.5)\end{array}$ & $\begin{array}{l}14,577.8(4272 \\
30,932)\end{array}$ \\
\hline 24 h (day 2) & $\begin{array}{l}50,284.8 \\
(4898.9)\end{array}$ & $\begin{array}{l}49,343.0(40,915 \\
57,468)\end{array}$ & 96 h (day 5) & $\begin{array}{l}16,682.3 \\
(6038.3)\end{array}$ & $\begin{array}{l}17,409.5(5769 \\
30,496)\end{array}$ \\
\hline 48 h (day 3) & $\begin{array}{l}40,738.2 \\
(6858.4)\end{array}$ & $\begin{array}{l}42,234.0(25,116 \\
\quad 48,412)\end{array}$ & 120 h (day 6) & $\begin{array}{l}16,131.3 \\
(6055.2)\end{array}$ & $\begin{array}{l}\text { 16,393.1 }(6194 \\
31,172)\end{array}$ \\
\hline 72 h (day 4) & $\begin{array}{l}32,845.9 \\
(9835.9)\end{array}$ & $\begin{array}{l}34,844.2(17,184 \\
\quad 47,450)\end{array}$ & 144 h (day 7) & $\begin{array}{l}16,752.1 \\
\quad(5184.2)\end{array}$ & $\begin{array}{l}17,763.1(8253 \\
27,535)\end{array}$ \\
\hline 96 h (day 5) & $\begin{array}{l}30,995.0 \\
\quad(6472.1)\end{array}$ & $\begin{array}{l}31,302.9(17,096 \\
\quad 40,586)\end{array}$ & 168 h (day 8) & $\begin{array}{l}16,825.5 \\
\quad(5096.0)\end{array}$ & $\begin{array}{l}\text { 17,720.6 (7924, } \\
28,291)\end{array}$ \\
\hline 168 h (day 8) & $\begin{array}{l}23,850.3 \\
(3898.4)\end{array}$ & $\begin{array}{l}24,244.0(14,678 \\
29,171)\end{array}$ & 240 h (day 11) & $\begin{array}{l}17,262.9 \\
(3702.0)\end{array}$ & $\begin{array}{l}17,417.3(10,274 \\
26,221)\end{array}$ \\
\hline 336 h (day 15) & $\begin{array}{l}15,930.7 \\
(3859.5)\end{array}$ & $\begin{array}{c}\text { 15,385.3 }(9234 \\
21,845)\end{array}$ & 336 h (day 15) & $\begin{array}{l}14,724.2 \\
(3519.9)\end{array}$ & $\begin{array}{l}14,354.4(7061 \\
22,925)\end{array}$ \\
\hline 504 h (day 22) & $\begin{array}{l}11,291.5 \\
(3860.4)\end{array}$ & $\begin{array}{c}11,739.8(4192 \\
16,073)\end{array}$ & 504 h (day 22) & $\begin{array}{l}11,235.9 \\
(2928.1)\end{array}$ & $\begin{array}{c}11,206.5(5036 \\
19,113)\end{array}$ \\
\hline 672 h (day 29) & $\begin{array}{l}10,115.7 \\
(2290.0)\end{array}$ & $\begin{array}{c}9867.8(7110 \\
14,351)\end{array}$ & 672 h (day 29) & $\begin{array}{l}7551.1 \\
\quad(2836.1)\end{array}$ & $\begin{array}{c}7460.2(2774 \\
15,352)\end{array}$ \\
\hline 1008 h (day 43) & $\begin{array}{l}5838.3 \\
\quad(1868.9)\end{array}$ & $5573.4(3288,8705)$ & 1008 h (day 43) & $\begin{array}{l}4720.3 \\
\quad(1827.4)\end{array}$ & $4745.4(1330,9297)$ \\
\hline 1344 h (day 57) & $\begin{array}{l}3146.7 \\
\quad(1275.2)\end{array}$ & $2979.6(1806,5546)$ & 1344 h (day 57) & $\begin{array}{l}2651.6 \\
(1345.4)\end{array}$ & $2605.3(595,6866)$ \\
\hline 1680 h (day 71) & $1916.6(936.5)$ & $1603.9(825,3375)$ & 1680 h (day 71) & $1365.7(931.5)$ & $1300.2(284,4730)$ \\
\hline
\end{tabular}

$I V$ intravenous, $P K$ pharmacokinetic, $S C$ subcutaneous, $S D$ standard deviation 
Table 3 Summary of AEs by SOC (safety population)

\begin{tabular}{|c|c|c|}
\hline & \multicolumn{2}{|c|}{ Number of volunteers (\%) } \\
\hline & $\begin{array}{l}\text { Belimumab } \\
200 \mathrm{mg} \mathrm{IV} \\
n=12\end{array}$ & $\begin{array}{l}\text { Belimumab } \\
200 \mathrm{mg} \mathrm{SC} \\
n=24\end{array}$ \\
\hline Adverse events & $11(91.7)$ & $24(100.0)$ \\
\hline $\begin{array}{l}\text { AE preferred terms } \\
\text { occurring in }>10 \% \\
\text { volunteers: }\end{array}$ & & \\
\hline Injection site pain & $0(0.0)$ & $19(79.2)$ \\
\hline Asthenia & $2(16.7)$ & $0(0.0)$ \\
\hline Oropharyngeal pain & $1(8.3)$ & $5(20.8)$ \\
\hline Mouth ulceration & $1(8.3)$ & $4(16.7)$ \\
\hline Diarrhea & $2(16.7)$ & $0(0.0)$ \\
\hline Positive bacterial test & $2(16.7)$ & $4(16.7)$ \\
\hline Neutrophil count decrease & $0(0.0)$ & $4(16.7)$ \\
\hline Occult blood positive & $0(0.0)$ & $4(16.7)$ \\
\hline Blood IgM decrease & $1(8.3)$ & $3(12.5)$ \\
\hline Blood uric acid increase & $2(16.7)$ & $3(12.5)$ \\
\hline WBC count increase & $2(16.7)$ & $0(0.0)$ \\
\hline $\begin{array}{l}\text { Upper respiratory tract } \\
\text { infection }\end{array}$ & $2(16.7)$ & $3(12.5)$ \\
\hline Hematuria & $0(0.0)$ & $3(12.5)$ \\
\hline Treatment-related AEs & $10(83.3)$ & $22(91.7)$ \\
\hline $\begin{array}{l}\text { Treatment-related AEs } \\
\text { preferred terms occurring } \\
\text { in }>10 \% \text { volunteers }\end{array}$ & & \\
\hline Oropharyngeal pain & $1(8.3)$ & $5(20.8)$ \\
\hline Mouth ulceration & $1(8.3)$ & $4(16.7)$ \\
\hline Diarrhea & $2(16.7)$ & $0(0.0)$ \\
\hline Positive bacterial test & $2(16.7)$ & $4(16.7)$ \\
\hline Neutrophil count decrease & $0(0.0)$ & $4(16.7)$ \\
\hline Occult blood positive & $0(0.0)$ & $4(16.7)$ \\
\hline Blood IgM decrease & $1(8.3)$ & $3(12.5)$ \\
\hline Blood uric acid increase & $2(16.7)$ & $3(12.5)$ \\
\hline WBC count increase & $2(16.7)$ & $0(0.0)$ \\
\hline
\end{tabular}

Table 3 continued

\begin{tabular}{lll}
\hline & \multicolumn{2}{l}{ Number of volunteers (\%) } \\
\cline { 2 - 3 } & $\begin{array}{l}\text { Belimumab } \\
\mathbf{2 0 0} \mathbf{~ m g ~ I V} \\
\boldsymbol{n}=\mathbf{1 2}\end{array}$ & $\begin{array}{l}\text { Belimumab } \\
\mathbf{2 0 0} \mathbf{~ m g ~ S C} \\
\boldsymbol{n}=\mathbf{2 4}\end{array}$ \\
\hline $\begin{array}{l}\text { Upper respiratory tract } \\
\text { infection }\end{array}$ & $2(16.7)$ & $3(12.5)$ \\
Hematuria & $0(0.0)$ & $3(12.5)$ \\
Asthenia & $2(16.7)$ & $0(0.0)$ \\
\hline
\end{tabular}

$A E$ adverse event, $I g M$ immunoglobulin $\mathrm{M}, I V$ intravenous, $S C$ subcutaneous, $S O C$ system organ class, $W B C$ white blood cell

${ }^{a}$ Volunteers could be counted in multiple AEs

neutrophil count decrease, and occult blood positive (16.7\% each; Table 3$)$.

There were 20 injection site reactions reported in $79.2 \%$ of volunteers in the SC group. The most frequently reported injection site reaction was injection site pain (79.2\%). No deaths, serious AEs (SAEs), or AEs leading to withdrawals were reported during this study.

A total of 17 clinical chemistry-related AEs were reported in ten $(27.8 \%)$ volunteers: two $(16.7 \%)$ volunteers in the IV group and eight $(33.3 \%)$ in the SC group (Table 4). Hematologyrelated AEs were reported in seven volunteers (19.4\%): three $(25.0 \%)$ volunteers in the IV group, and four $(16.7 \%)$ volunteers in the SC group (Table 4). Urinalysis-related AEs were reported in nine $(37.5 \%)$ volunteers in the SC group and none in the IV group (Table 4). Four clinically significant AEs of decreased immunoglobulin $\mathrm{M}(\mathrm{IgM} ;<0.4 \mathrm{~g} / \mathrm{L})$ levels were reported in one volunteer in the IV group and three $(12.5 \%)$ volunteers in the SC group (Table 4). All clinically relevant chemistry-related AEs were mild in severity, and most were considered by the investigator as related to belimumab and were resolved without treatment. Clinically significant abnormality in ECG parameters was reported in two volunteers in the SC group on day 71 (follow-up visit). The 
Table 4 AEs related to the clinical laboratory evaluations, ECG, and vital signs by SOC (safety population)

\begin{tabular}{|c|c|c|c|c|}
\hline \multirow[t]{2}{*}{ Clinically relevant AEs } & \multicolumn{2}{|c|}{$\begin{array}{l}\text { Belimumab } 200 \mathrm{mg} \mathrm{IV} \\
n=12\end{array}$} & \multicolumn{2}{|c|}{$\begin{array}{l}\text { Belimumab } 200 \mathrm{mg} \mathrm{SC} \\
n=24\end{array}$} \\
\hline & $\overline{n(\%)^{\mathrm{a}}}$ & No. of AEs & $\overline{n(\%)^{\mathrm{a}}}$ & No. of AEs \\
\hline Clinical chemistry & $2(16.7)$ & 4 & $8(33.3)$ & 13 \\
\hline $\mathrm{ALT}>50 \mathrm{IU} / 1$ & $0(0.0)$ & 0 & $2(8.3)$ & 3 \\
\hline $\mathrm{AST}>40 \mathrm{IU} / 1$ & $0(0.0)$ & 0 & $1(4.2)$ & 1 \\
\hline Blood bilirubin $>20.5 \mu \mathrm{mol} / \mathrm{l}$ & $1(8.3)$ & 1 & $1(4.2)$ & 2 \\
\hline Blood creatinine $>73 \mu \mathrm{mol} / \mathrm{l}$ & $1(8.3)$ & 1 & $0(0.0)$ & 0 \\
\hline Blood glucose $>6.1 \mathrm{mmol} / \mathrm{l}$ & $0(0.0)$ & 0 & $1(4.2)$ & 1 \\
\hline Blood triglycerides $>1.69 \mathrm{mmol} / \mathrm{l}$ & $0(0.0)$ & 0 & $1(4.2)$ & 1 \\
\hline Blood uric acid $>350 \mu \mathrm{mol} / \mathrm{l}$ & $2(16.7)$ & 2 & $3(12.5)$ & 3 \\
\hline GGT $>60 \mathrm{IU} / 1$ & $0(0.0)$ & 0 & $1(4.2)$ & 2 \\
\hline Hematology & $3(25.0)$ & 4 & $4(16.7)$ & 9 \\
\hline Hematocrit $<0.35$, unit: fraction of 1 & $0(0.0)$ & 0 & $1(4.2)$ & 1 \\
\hline $\mathrm{Hb}<115 \mathrm{~g} / \mathrm{l}$ & $1(8.3)$ & 1 & $2(8.3)$ & 4 \\
\hline Neutrophil count $<1.8 \times 10^{9} / 1$ & $0(0.0)$ & 0 & $4(16.7)$ & 4 \\
\hline Neutrophil count $>6.3 \times 10^{9} / 1$ & $1(8.3)$ & 1 & $0(0.0)$ & 0 \\
\hline WBC count $>9.5 \times 10^{9} / 1$ & $2(16.7)$ & 2 & $0(0.0)$ & 0 \\
\hline Urinalysis & $0(0.0)$ & 0 & $9(37.5)$ & 11 \\
\hline Hematuria & $0(0.0)$ & 0 & $3(12.5)$ & 3 \\
\hline Occult blood positive & $0(0.0)$ & 0 & $4(16.7)$ & 5 \\
\hline Urine ketone bodies present & $0(0.0)$ & 0 & $2(8.3)$ & 2 \\
\hline Glucose urine present & $0(0.0)$ & 0 & $1(4.2)$ & 1 \\
\hline Immunoglobulin & $1(8.3)$ & 1 & $3(12.5)$ & 3 \\
\hline Blood IgM $<0.4 \mathrm{~g} / \mathrm{l}$ & $1(8.3)$ & 1 & $3(12.5)$ & 3 \\
\hline ECG and vital signs & $0(0.0)$ & 0 & $2(8.3)$ & 3 \\
\hline $\mathrm{T}$ wave abnormal & $0(0.0)$ & 0 & $2(8.3)$ & 2 \\
\hline Heart rate increased & $0(0.0)$ & 0 & $1(4.2)$ & 1 \\
\hline
\end{tabular}

$A E$ adverse event, $A L T$ alanine aminotransferase, $A S T$ aspartate aminotransferase, $E C G$ electrocardiogram, $G G T$ gammaglutamyl transferase, $H b$ hemoglobin, $I g M$ immunoglobulin $\mathrm{M}, I U$ international unit, $I V$ intravenous, $S C$ subcutaneous, SOC system organ class, $W B C$ white blood cells

${ }^{a}$ Volunteer could be counted in multiple AEs related to clinical laboratory evaluations, ECG, or vital signs 
events in both volunteers were of mild intensity and were considered by the investigator as possibly not related to belimumab. No treatment-related or clinically relevant changes in vital sign values were observed.

\section{DISCUSSION}

The current phase 1 study investigated the PK (concentration-time profile) and safety of belimumab administered as a single IV or SC 200-mg doses in healthy Chinese volunteers. This is the first study to investigate SC belimumab in a Chinese population.

The SC belimumab injection exhibited slower absorption compared with the IV infusion. The maximum serum belimumab concentrations were observed at the completion of IV infusion ( $1 \mathrm{~h}$ after the start of infusion) and 11 days after SC injection. This is expected with high molecular weight monoclonal antibodies absorbed via the lymphatic system [36, 37]. The maximum serum concentration of belimumab after SC administration was approximately 70\% lower than that after IV administration. However, both belimumab formulations were cleared in the same length of time after administration (71 days), which indicates that the administration method does not affect the elimination of belimumab.

The belimumab concentration-time profiles observed in this study are in agreement with those observed in a previous post hoc modeling and simulation analysis comparing belimumab 200-240 mg IV and $200 \mathrm{mg}$ SC administration in US and Japanese populations [38]. In this post hoc analysis conducted by Yapa et al., the peak of the mean serum belimumab concentration for the single-dose IV formulation was observed on day 1 at approximately 70,000 ng/ $\mathrm{ml}$ in the US and $40,000 \mathrm{ng} / \mathrm{ml}$ in Japanese populations, and for the single-dose SC formulation, the peak was observed at day 4 at approximately $20,000 \mathrm{ng} / \mathrm{ml}$ in both populations [38]. Similarly, in the current study, the mean serum belimumab concentration peak for the IV formulation was also observed at day 1 at $64,474.6 \mathrm{ng} / \mathrm{ml}$; however, for the SC formulation, the peak was observed slightly later, at day
11 at $17,262.9 \mathrm{ng} / \mathrm{ml}$. Irrespective of the formulation, belimumab was eliminated by day 71 , which is consistent with previously reported belimumab results [38]. The belimumab $200 \mathrm{mg}$ IV and SC concentration-time profiles of the current study are also similar to that obtained in a single-dose PK study with belimumab $200 \mathrm{mg}$ IV (day 1 [peak]: $\sim 65,000 \mathrm{ng} / \mathrm{ml}$; day 21: 18,000 ng/ml; day 71: 4400 ng/ml) and SC (day 7 [peak]: 25,000 ng/ml; day 29: 17,000 ng/ml; day 71: 4000 ng/ml) performed in healthy Japanese volunteers [36].

Although most volunteers $(91.7 \%$ from the IV group and $100 \%$ from the SC group) experienced an $\mathrm{AE}$ in the current study, most were of mild severity and resolved without treatment. No SAEs AEs leading to withdrawals, or deaths were reported throughout the duration of this study, which is in agreement with the safety results observed in previous SC belimumab studies in healthy volunteers [36, 39]. The most frequently reported $\mathrm{AE}$ in the $\mathrm{SC}$ group of this study was injection site pain, which was also one of the most frequently reported AEs in previous belimumab studies in healthy US and Japanese volunteers [36, 39]. All injection site pain AEs reported in the current study and all but one in the US study were of mild intensity [39]. In a previous phase 3 SC belimumab study in patients with SLE (BLISS-SC; ClinicalTrials.gov NCT01484496), 81\% of patients experienced $\geq 1 \mathrm{AE}$ [27]. This proportion was lower than in the current study, in which $100 \%$ of healthy volunteers in the SC group experienced an $\mathrm{AE}$. The most frequently reported $\mathrm{AE}$ in the BLISS-SC study was infections and infestations [27], which were also the most frequently reported treatment-related AEs in the current study. In addition, only $6.1 \%$ of belimumab patients in BLISS-SC experienced local injection site reactions [27], compared with $79.2 \%$ of volunteers in the current study. Furthermore, while $10.8 \%$ of patients with SLE in the BLISSSC study experienced SAEs [27], no SAEs were reported in the healthy Chinese volunteers in the current study.

Neutropenia occurred in four volunteers receiving belimumab $200 \mathrm{mg}$ SC in this study. While two of the cases were considered by the investigator as possibly not related to 
belimumab, the neutropenia in two volunteers was deemed by the investigator as treatmentrelated. All cases were mild in intensity and resolved without treatment.

There was a decrease in blood IgM levels reported in one volunteer receiving belimumab $200 \mathrm{mg}$ IV and three volunteers receiving belimumab $200 \mathrm{mg}$ SC. IgM autoantibodies constitute a protective barrier to viral and bacterial infections, and their induced decrease following belimumab administration could suggest possible immunosuppression. Immunoglobulin abnormalities have been reported to be a frequent occurrence in patients receiving B-cell therapy and therefore immunoglobulin levels should be monitored throughout B-cell therapy [40].

Despite a higher proportion of volunteers receiving belimumab $200 \mathrm{mg}$ SC $(37.5 \%, n=9$ / 24) experiencing urinalysis-related AEs compared with those receiving belimumab $200 \mathrm{mg}$ IV $(0.0 \%, n=0 / 12), 9 / 11(81.8 \%$ of total urinalysis-related AEs) of the events (three hematuria, five occult blood positive, and one urine ketone bodies present) were considered treatment-related, all were mild in intensity and all were resolved without treatment. Combined with the small size of the treatment groups and the fact that urinalysis-related AEs were of mild intensity and generally resolved without treatment by end of the study, the difference in urinalysis-related AEs between treatment groups were not considered to be clinically significant.

In addition to acceptable PK and safety profiles, belimumab $200 \mathrm{mg}$ SC may be preferable to the IV route of belimumab administration in China, since IV administration, in general, poses several disadvantages for patients including substantial travel time to clinics, infusion time, time for post-infusion monitoring, and substantial financial expenses related to clinical supplies and personnel [27]. In addition, the recommended dose of IV belimumab for the treatment of SLE is $10 \mathrm{mg} / \mathrm{kg}$ once every 4 weeks [29-31], rather than the $200 \mathrm{mg}$ administered in this study. Therefore, the lower dose of belimumab $200 \mathrm{mg}$ IV in this study may have minimized the proportion of AEs experienced and may not be comparable in safety evaluation to the recommended belimumab $10 \mathrm{mg} / \mathrm{kg}$ IV dose administered every 4 weeks.

This study has a few limitations including a single-dose design, and lack of statistical comparisons, which precludes a full assessment of the PK and long-term safety of SC belimumab in Chinese volunteers. Additionally, this phase 1 study was conducted in young (mean age 28.7 years), healthy, predominantly male (81\%) volunteers, which may not be generalizable to the wider patient population with SLE.

\section{CONCLUSIONS}

In conclusion, concentration-time profiles of belimumab $200 \mathrm{mg}$ SC and IV administrations in healthy Chinese volunteers were similar to previous studies in the USA and Japan. Safety and tolerability profiles were acceptable. Although a greater proportion of volunteers from the SC treatment group experienced urinalysis-related AEs compared with the IV treatment group, all were of mild intensity and resolved without treatment. These findings support the use of the SC dose in Chinese patients with SLE.

\section{ACKNOWLEDGEMENTS}

We thank the volunteers and their families and all the investigators and site personnel for participating in this trial.

Funding. This study (GSK Study 209629; NCT04136145) was funded by GlaxoSmithKline, Shanghai, China. The journal's Rapid Service and Open Access fees were also funded by GlaxoSmithKline, Shanghai, China.

Medical Writing, Editorial, and Other Assistance. Medical writing support was provided by Helen Taylor, PhD, of Fishawack Indicia Ltd, UK, part of Fishawack Health, and was funded by GSK.

Authorship. All named authors meet the International Committee of Medical Journal Editors (ICMJE) criteria for authorship for this 
article, take responsibility for the integrity of the work as a whole, and have given their approval for this version to be published.

Author Contributions XM, HL, SW, DP, AZ, $\mathrm{SF}$, and XZ designed the study. HL and QW were responsible for data acquisition. XM, SW, DP, $\mathrm{SF}$, and $\mathrm{XZ}$ contributed to the data analysis and interpretation.

List of Investigators. HL and QW.

\section{DATA AVAILABILITY}

The datasets generated during and/or analyzed during the current study are available in the ClinicalStudyDataRequest.com repository, www.clinicalstudydatarequest.com.

\section{Declarations}

Disclosures Xuan Zhou is an employee of GSK and holds stocks and shares in the company. Shunquan Wu, Di Pu, Amber Zhang and Sun Fang were employees of GSK at the time of the study. Amber Zhang and Sun Fang held stocks and shares in the company. Shunquan Wu's new affiliation is China SHIYAO Pharmaceutical Group Co., Ltd. Di Pu's new affiliation is FibroGen China. Amber Zhang's new affiliation is Fresenius-kabi China Co., Ltd. Sun Fang's new affiliation is Shanghai LianBio Development Co., Ltd. Xianmin Meng, Qianqian Wang and Hongzhou Lu have nothing to disclose.

Compliance with Ethical Guidelines The study procedure, any amendments, informed consent, and any other information required pre-approval were in accordance with the ethical standards of the national, regional, or investigational center ethics committee or institutional review board, in accordance with the International Council on Harmonization of Technical Requirements for Registration of Pharmaceuticals for Human Use (ICH) Good Clinical Practice (GCP) and applicable countryspecific requirements, including US 21 Code of Federal Regulations (CFR) 312.3(b) for constitution of independent ethics committees. Investigators were trained and provided written commitments to perform the study in accordance with GCPs, the approved study protocol, as defined in ICH E3, Sect. 9.6, all applicable subject privacy requirements and the ethical principles in the Declaration of Helsinki. Informed consent was obtained from all healthy volunteers included in the study.

Open Access. This article is licensed under a Creative Commons Attribution-NonCommercial 4.0 International License, which permits any non-commercial use, sharing, adaptation, distribution and reproduction in any medium or format, as long as you give appropriate credit to the original author(s) and the source, provide a link to the Creative Commons licence, and indicate if changes were made. The images or other third party material in this article are included in the article's Creative Commons licence, unless indicated otherwise in a credit line to the material. If material is not included in the article's Creative Commons licence and your intended use is not permitted by statutory regulation or exceeds the permitted use, you will need to obtain permission directly from the copyright holder. To view a copy of this licence, visit http://creativecommons.org/licenses/by$\mathrm{nc} / 4.0 /$.

\section{REFERENCES}

1. Stohl W, Hiepe F, Latinis KM, Thomas M, Scheinberg MA, Clarke A, et al. Belimumab reduces autoantibodies, normalizes low complement levels, and reduces select $B$ cell populations in patients with systemic lupus erythematosus. Arthritis Rheum. 2012;64:2328-37.

2. Urowitz MB, Gladman DD, Ibanez D, Fortin PR, Bae SC, Gordon C, et al. Evolution of disease burden over five years in a multicenter inception systemic lupus erythematosus cohort. Arthritis Care Res. 2012;64:132-7.

3. Chambers SA, Allen E, Rahman A, Isenberg D. Damage and mortality in a group of British patients with systemic lupus erythematosus followed up for over 10 years. Rheumatology. 2009;48:673-5.

4. Lopez R, Davidson JE, Beeby MD, Egger PJ, Isenberg DA. Lupus disease activity and the risk of 
subsequent organ damage and mortality in a large lupus cohort. Rheumatology. 2012;51:491-8.

5. Furie R, Petri M, Zamani O, Cervera R, Wallace DJ, Tegzova D, et al. A phase III, randomized, placebocontrolled study of belimumab, a monoclonal antibody that inhibits B lymphocyte stimulator, in patients with systemic lupus erythematosus. Arthritis Rheum. 2011;63:3918-30.

6. Lech M, Anders HJ. The pathogenesis of lupus nephritis. J Am Soc Nephrol. 2013;24:1357-66.

7. Zhang F, Bae SC, Bass D, Chu M, Egginton S, Gordon $\mathrm{D}$, et al. A pivotal phase III, randomised, placebo-controlled study of belimumab in patients with systemic lupus erythematosus located in China, Japan and South Korea. Ann Rheum Dis. 2018;77:355-63.

8. McElhone K, Abbott J, Teh LS. A review of health related quality of life in systemic lupus erythematosus. Lupus. 2006;15:633-43.

9. Lau CS, Mak A. The socioeconomic burden of SLE. Nat Rev Rheumatol. 2009;5:400-4.

10. Feldman CH, Hiraki LT, Liu J, Fischer MA, Solomon $\mathrm{DH}$, Alarcon GS, et al. Epidemiology and sociodemographics of systemic lupus erythematosus and lupus nephritis among US adults with Medicaid coverage, 2000-2004. Arthritis Rheum. 2013;65: 753-63.

11. Furst DE, Clarke AE, Fernandes AW, Bancroft T, Greth W, Iorga SR. Incidence and prevalence of adult systemic lupus erythematosus in a large US managed-care population. Lupus. 2013;22:99-105.

12. Voss A, Green A, Junker P. Systemic lupus erythematosus in Denmark: clinical and epidemiological characterization of a county-based cohort. Scand J Rheumatol. 1998;27:98-105.

13. Somers EC, Thomas SL, Smeeth L, Schoonen WM, Hall AJ. Incidence of systemic lupus erythematosus in the United Kingdom, 1990-1999. Arthritis Rheum. 2007;57:612-8.

14. Nightingale AL, Farmer RD, de Vries CS. Incidence of clinically diagnosed systemic lupus erythematosus 1992-1998 using the UK General Practice Research Database. Pharmacoepidemiol Drug Saf. 2006;15:656-61.

15. Rees F, Doherty M, Grainge M, Davenport G, Lanyon P, Zhang W. The incidence and prevalence of systemic lupus erythematosus in the UK, 1999-2012. Ann Rheum Dis. 2016;75:136-41.
16. Shim JS, Sung YK, Joo YB, Lee HS, Bae SC. Prevalence and incidence of systemic lupus erythematosus in South Korea. Rheumatol Int. 2014;34:909-17.

17. Mok CC, To CH, Ho LY, Yu KL. Incidence and mortality of systemic lupus erythematosus in a southern Chinese population, 2000-2006. J Rheumatol. 2008;35:1978-82.

18. Mok CC. Epidemiology and survival of systemic lupus erythematosus in Hong Kong Chinese. Lupus. 2011;20:767-71.

19. Kang SC, Hwang SJ, Chang YS, Chou CT, Tsai CY. Characteristics of comorbidities and costs among patients who died from systemic lupus erythematosus in Taiwan. Arch Med Sci. 2012;8:690-6.

20. Yu KH, See LC, Kuo CF, Chou IJ, Chou MJ. Prevalence and incidence in patients with autoimmune rheumatic diseases: a nationwide population-based study in Taiwan. Arthritis Care Res. 2013;65: 244-50.

21. Wang Z, Wang Y, Zhu R, Tian X, Xu D, Wang Q, et al. Long-term survival and death causes of systemic lupus erythematosus in China: a systemic review of observational studies. Medicine. 2015;94: e794.

22. Golder V, Connelly K, Staples M, Morand E, Hoi A. Association of Asian ethnicity with disease activity in SLE: an observational study from the Monash Lupus Clinic. Lupus. 2013;22:1425-30.

23. Cancro MP, D'Cruz DP, Khamashta MA. The role of B lymphocyte stimulator (BLyS) in systemic lupus erythematosus. J Clin Invest. 2009;119:1066-73.

24. Browning JL. B cells move to centre stage: novel opportunities for autoimmune disease treatment. Nat Rev Drug Discov. 2006;5:564-76.

25. GlaxoSmithKline. Belimumab European Union summary of product characteristics. https://www. ema.europa.eu/en/documents/product-information /benlysta-epar-product-information_en.pdf. Accessed 9 Nov 2020.

26. Navarra SV, Guzmán RM, Gallacher AE, Hall S, Levy RA, Jimenez RE, et al. Efficacy and safety of belimumab in patients with active systemic lupus erythematosus: a randomised, placebo-controlled, phase 3 trial. The Lancet. 2011;377:721-31.

27. Stohl W, Schwarting A, Okada M, Scheinberg M, Doria A, Hammer AE, et al. Efficacy and safety of subcutaneous belimumab in systemic lupus erythematosus: a fifty-two-week randomized, doubleblind, placebo-controlled study. Arthritis Rheumatol. 2017;69:1016-27. 
28. Wallace DJ, Ginzler EM, Merrill JT, Furie RA, Stohl W, Chatham WW, et al. Safety and efficacy of belimumab plus standard therapy for up to thirteen years in patients with systemic lupus erythematosus. Arthritis Rheumatol. 2019;71:1125-34.

29. GlaxoSmithKline. Belimumab US prescribing information. https://www.accessdata.fda.gov/drug satfda_docs/label/2019/125370s064,761043s007lbl. pdf. Accessed 9 Nov 2020.

30. GlaxoSmithKline. Belimumab Canada product monograph. https://pdf.hres.ca/dpd_pm/000523 51.PDF. Accessed 9 Nov 2020.

31. GlaxoSmithKline. Belimumab Japan results of deliberation. https://www.pmda.go.jp/files/ 000235894.pdf. Accessed 9 Nov 2020.

32. GlaxoSmithKline. Benlysta, the world's first biologic therapy for the treatment of systemic lupus erythematosus (SLE), now approved in mainland China. https://www.gsk-china.com/en-gb/media/ press-releases/2019/benlysta-the-world-s-first-biologictherapy-for-the-treatment-of-systemic-lupus-erythe matosus-sle-now-approved-in-mainland-china/. Accessed 09 Nov 2020.

33. GlaxoSmithKline. The world's first biologic therapy for patients with SLE, Benlysta receives NMPA approval for children with lupus aged five years and above. https://www.gsk-china.com/en-gb/media/ press-releases/2020/the-world-s-first-biologicthera py-for-patients-with-sle-benlysta-receives-nmpa-ap proval-for-children-with-lupus-aged-five-years-andabove/. Accessed March 2021.

34. Struemper H, Thapar M, Roth D. Population pharmacokinetic and pharmacodynamic analysis of belimumab administered subcutaneously in healthy volunteers and patients with systemic lupus erythematosus. Clin Pharmacokinet. 2018;57: 717-28.

35. McKenzie B. Clinical trials handbook - Asia Pacific. https://www.bakermckenzie.com/-/media/files/in sight/publications/2019/healthcare/ap/dsc125067_ clinical-trials-handbook-china.pdf?la=en. Accessed August 2021.

36. Shida Y, Takahashi N, Sakamoto T, Ino H, Endo A, Hirama T. The pharmacokinetics and safety profiles of belimumab after single subcutaneous and intravenous doses in healthy Japanese volunteers. J Clin Pharm Ther. 2014;39:97-101.

37. Wang W, Wang EQ, Balthasar JP. Monoclonal antibody pharmacokinetics and pharmacodynamics. Clin Pharmacol Ther. 2008;84:548-58.

38. Yapa SW, Roth D, Gordon D, Struemper H. Comparison of intravenous and subcutaneous exposure supporting dose selection of subcutaneous belimumab systemic lupus erythematosus Phase 3 program. Lupus. 2016;25:1448-55.

39. Cai WW, Fiscella M, Chen C, Zhong ZJ, Freimuth WW, Subich DC. Bioavailability, pharmacokinetics, and safety of belimumab administered subcutaneously in healthy subjects. Clin Pharmacol Drug Dev. 2013;2:349-57.

40. Cuadrado MJ, Calatayud I, Urquizu-Padilla M, Wijetilleka S, Kiani-Alikhan S, Karim MY. Immunoglobulin abnormalities are frequent in patients with lupus nephritis. BMC Rheumatol. 2019;3:30. 